6. KorobkeEv, A.A. Changes in the structural elements of the temporomandibular joint with distal occlusion / A.A. Korobkeev, D.A. Domenyuk, E.G. Vedeshina, V.V. Konnov, O.Yu. Lezhnina, Ya.A. Korobkeeva / / Medical news of North Caucasus. 2017. - Vol. 12. - № 1. - P. 72-76. (In Russ., English abstract). DOI: 10.14300/mnnc.2017.12020.

7. KorobKeEv, A.A. Anatomical features of the interdependence of the basic parameters of the dental arches of the upper and lower jaws of man / A.A. Korobkeev, D.A. Domenyuk, V.V. Shkarin, S.V. Dmitrienko, L.D. Weisheim, V.V. Konov // Medical news of North Caucasus. 2018. - Vol. 13. - № 1-1. P. 66-69. (In Russ., English abstract). DOI: 10.14300/ mnnc.2018.13019.
8. LePILIN A.V., Fomin I.V., DomenyUk D.A., DMitrienko S.V. Diagnostic value of cephalometric parameters at graphic reproduction of tooth dental arches in primary teeth occlusion // Archiv EuroMedica, 2018. - T. 8. - № 1. - C. 37-38.

9. Radiological specifics of temporomandibular joint structure in case of dentition issues complicated with distal occlusion / S.V. Konnov, A.A. Bizyaev, V.V. Konnov, E.V. Pichugina, S.N. Salnikova, A.S. Khodorich, V.A. Mikailova // Archiv EuroMedica. - 2018. - T. 8, № 1. - C. 39-40.

10. Shkarin V., Domenyuk D., Lepilin A., Fomin I., DMitrienko S. Odontometric indices fluctuation in people with physiological occlusion // Archiv EuroMedica, 2018. - T. 8. - № 1. - C. 12-18.

\title{
ANATOMICAL FEATURES DETERMINING THE OPTIMAL INCLINATION ANGLE OF THE FRONT TEETH PALATAL FACETS
}

\section{A. Bizyaev, V. Konnov, D. Razakov, N. Bulkina, D. Maslennikov, R. Mukhamedov, S. Konnov}

Introduction. Dentition defects are among the main causes behind maxillofacial functional disorders, which lead to dentition and occlusion deformations, morphological changes in the temporomandibular joints as well impaired chewing, speech articulation and the aesthetics $[1,4,6,8,9]$. Localizing such defects in the upper jaw anterior area poses considerable difficulties when modeling prosthetic teeth, namely, recreating the inclination of the upper anterior teeth palatal facets in order to restore the aesthetics, speech, the sagittal incisor path, and an optimal dentition opening related to the temporomandibular joint function $[2,3,5,7,10]$.

AIM OF STUDY - to identify anatomical features determining the optimal inclination angle of the front teeth palatal facets at upper anterior bounded edentuous space.

Materials And methods. We examined 150 people, aged $19-25$, with intact dentition and orthognathic occlusion. Anatomical impressions were obtained and jaw cast models made where the inclination angles were measured for the alveolar, middle and palatal third of the anterior part of the palatal vault, as well as the inclination angles of the upper jaw anterior teeth palatal facets. The measurements were taken with a respectively developed device (useful model patent of the Russian Federation, \#53141) following the method of determining the inclination angles of the upper jaw front teeth palatal facets when designing dentures. To measure the angle determining the palatal vault inclination and the anterior teeth palatal facets inclination, the ratio was determined for the palate height at the intercanine level line to the distance from the intercanine line to the central incisors.

REsults. The cast models were used to identify and mark the point of palatal vault greatest depth perpendicular to the point of the median palatine suture intersects with a line drawn at the level of the alveolar process tops between the second premolars and the first molars. A strip of foil was put from this point to the top of the incisor papilla, which helped determine the anterior palatal vault length. This length was divided into three equal parts - alveolar, middle and palatal.

The study revealed that the inclination angle of the front teeth palatal facets varied from $34^{\circ}$ to $55^{\circ}$, whereas the inclination angle of the mid-third of the anterior palatal vault was equal to the palatal facets inclination angle of the anterior teeth with an average precision of $84 \%$, and ranged from $32^{\circ}$ to $57 \pm 2^{\circ}$.

This means that restoring the angle of the denture mid-part inclination towards the horizontal plane, which is equal to the inclination angle of the mid-third of the palatal vault anterior part, we will recover the optimal conditions for correct speech articulation and aesthetics, which will prompt the patient's adjustment to the denture.

Conclusions. The above allows concluding that the palatal facets inclination angle of the front teeth is equal to the inclination angle of the anterior 
palatal vault mid-third. The data obtained concerning the inclination will play a decisive role when developing individual cast models to design the palatal surface of a fixed dental prosthesis. The technique in question allows employing fixed dentures to obtain optimal and reliable parameters for restoring the upper front teeth in case part or all of them are missing. The obtained data are valid for an orthognathic occlusion with no transversal or sagittal issues.

\section{REFERENCES}

1. Domenyuk D.A., Porfyriadis M.P., DMITRIENKo S.V. Major telerenthengogram indicators in people with various growth types of facial area // Archiv EuroMedica, 2018. - T. 8. - № 2. P. 19-24.

2. Domenyuk D.A., Vedeshina E.G., Dmitrienko S.V. The use of craniometric and morphological studies in the assessment of structural elements of the temporomandibular joint. Kubanskij nauchnyj medicinskij vestnik. 2017;1(1):33-40. (In Russ.) DOI:10.25207/1608-6228-2017-1-33-40.

3. Clinical features of temporomandibular joint dysfunction in patients with mesial occlusion complicated by dentition defects / V. Konnov, D. Razakov, S. Salnikova, R. Mukhamedov, E. Pylaev, S. Konnov, V. Mikailova // Archiv EuroMedica. - 2018. - vol. 8. - num.1. - p. 27-32.

4. Radiological specifics of temporomandibular joint structure in case of dentition issues compli-cated with distal occlusion / S. Konnov, A. Bizyaev, V. Konnov, C. Pichugina, S. Salnikova, A. Khodorich, V. Mikailova // Archiv EuroMedica. - 2018. - vol. 8. - num.1. - p. 39-40.
5. Specifics of occlusion disturbances in adults with distal occlusion due to dentition defects // S. Konnov, A. Arushanyan, V. Konnov, D. Razakov, R. Mukhamedov, C. Pichugina, V. Mikailova // Archiv EuroMedica. - 2018. - vol. 8. - num.1. - p. 40-41.

6. Functional status of masticatory muscles at occlusion disturbances accompanied with displaced mandible / S. Konnov, D. Razakov, V. Konnov, A. Arushanyan, R. Mukhamedov, A. Khodorich, V. Mikailova // Archiv EuroMedica. - 2018. - vol. 8. - num.1. p. 41-42.

7. Clinical image of temporomandibular joint dysfunction in patients with dentition defects issues complicated with displaced mandible / S. Konnov, C. Pichugina, V. Konnov, A. Bizyaev, S. Salnikova, A. Arushanyan, V. Mikailova // Archiv EuroMedica. 2018. - vol. 8. - num.1. - p. 42-43.

8. Konnov V.V., Davydov B.N., Vedeshina E.G., Domenyuk D.A. The morphology of the temporomandibular joint in normal occlusion and distal occlusion complicated by defects of dentitions (Part I). The Dental Institute. 2017; 74(1):92-94. (In Russ.).

9. Konnov V.V., Davydov B.N., Vedeshina E.G., Domenyuk D.A. The morphology of the temporomandibular joint in normal occlusion and distal occlusion complicated by defects of dentitions (Part II). The Dental Institute. 2017; 75(2): 66-69. (In Russ.).

10. KorobkeEv, A.A. Anatomical features of the interdependence of the basic parameters of the dental arches of the upper and lower jaws of man / A.A. Korobkeev, D.A. Domenyuk, V.V. Shkarin, S.V. Dmitrienko, L.D. Weisheim, V.V. Konov // Medical news of North Caucasus. 2018. - Vol. 13. - № 1-1. P. 66-69. (In Russ., English abstract). DOI: 10.14300/ mnnc.2018.13019.

\section{THE FUNCTIONAL STATUS OF MASTICATORY MUSCLES AT DISPLACED MANDIBLE BASED ON ELECTROMYOGRAPHIC DATA}

\section{S. Konnov, A. Arushanyan, E. Pichugina, N. Bulkina, V. Konnov, M. Vorobyeva}

INTRODUCTION. The functional status of the temporomandibular joint and masticatory muscles depends on the dentition integrity, on the type of dentures used to compensate for the dentition issues, on the type and nature of the respective occlusion disorders, and on the degree of complications, the most severe of them being a displaced mandible $[1,2,5,8,10]$. One of the reliable methods for assessing masticatory muscles functional disorders is electromyographic examination $[3,4,6,7,9]$.

AIM OF STUDY - to investigate electromyographic data obtained through studying mastica-tory muscles in adult patients featuring dentition issues complicated with a displaced mandible.

Materials and methods. We carried out electromyographic examination of the masticatory muscles in 60 patients (aged 30 to 55) suffering from dentition issues complicated with posterior mandible dislocation. The patients were divided into two groups. Group 1 included 30 patients who had had the pathology for more than a year, while the other group includ- 